\title{
Competition or Catastrophe: A Mixed Method Study on the Influence of Class Rank on Course Decisions
}

\author{
Shannon Breuer ${ }^{1}$ and Kimberly Grosenbacher ${ }^{\#}$ \\ ${ }^{1}$ Boerne-Samuel V. Champion High School, Boerne, TX, USA \\ \#Advisor
}

\section{$\underline{\text { ABSTRACT }}$}

This study analyzed the extent to which class rank competition influences individual class selection by juniors at a high school in the Texas Hill Country and determined if its effects vary among students of different rankings. Students of both high and low rankings were interviewed to determine their perceptions towards, and behavior in response to academic competition. Subject responses generally correlated to one of three themes: class rank as an academic motivator, the influence of ranking on mental health, and student suggested improvements. The results suggested that GPA played a significant role in many student's decisions concerning their courses, specifically in encouraging them to take AP, Dual Credit, and Honors classes- regardless of whether they were high or low ranking.

\section{Introduction}

In the last two decades, the quintessential "high school environment" has evolved beyond a basic secondary level education and has become a fundamental element in determining a student's success in college and their professional careers. As academic life continues to become more strenuous, the expectation for students to balance AP (Advanced Placement), IB (International Baccalaureate), and Honors classes, multiple varsity sports, clubs and extracurricular activities, and leave time for any personal hobbies appears to be becoming increasingly unattainable; along with this, the highly competitive environment leaves students inevitably competing with their peers to be the best of the best. Class rank is a variable that has emerged as an important determinant of student achievement within the scholastic environment. The College Board defines class rank as "a mathematical summary of a student's academic record compared to those of other students in the class" (2021). It is computed by placing students in order of their grade point averages (GPA) which reflect their grades in conjunction with the difficulty of their course load.

It is the nature of a class ranking system to encourage competition between students. This creates the need for a greater understanding of its possible influence on students' behavior and mental well-being. Differences in GPA calculation methods coupled with the pressures of academic competition may cause students to attempt to maximize their success with minimal effort, such as taking specific classes for the advancement of their class standing. This raises the argument that such behavior undermines the intended purpose of ranking in accurately displaying student achievement (Gilman \& Swan, 1989). These findings promote the need for research that assess the benefits and detriments of the class ranking system as a whole.

\section{Literature Review}

In reference to existing research regarding class rank, most studies compare the different methods of which rank is calculated or examine various goal structures for promoting student success. However, few studies have been conducted specifically examining the impact of rank competition on student perceptions of themselves, their academics, and their peers. A study conducted by David Bergin and Helen Cooks of the University of Toledo explored 
academic competition among high achieving students of color; qualitative interviews revealed that most students recognized competition among their peers, although whether it was seen as positive or negative varied from student to student. Bergin and Cooks also found that, notwithstanding their academic prowess, student goals "focused on grades and competition rather than learning for an authentic purpose" (2000). The researchers identified that the students "had little to say about the content of their classes or its usefulness" (Bergin \& Cooks, 2000). This displays one of the primary arguments against class rank, suggesting that academic competition distracts from authentic learning. The study did, however, find that students with "high perceptions of ability" are more likely to respond positively to competition (Bergin \& Cooks, 2000). This suggests that certain students who view their rank positively may see it as a motivator to perform better academically, thereby causing a potential improvement in their grades; these findings further fuel the debate between possible ramifications of an issued class rank (Bergin \& Cooks, 2000). Studies on class rank commonly include students of similar academic proficiencies, however for this research it was hypothesized that competition is heightened among the students with the highest rankings.

When discussing the psychological impacts of different classroom settings, educational psychology specialists Dr. Carole Ames and Dr. Jennifer Archer have defined two goal orientations which influence student perceptions of their personal academic performance in comparison to their peers. With a performance goal set, students focus on "being judged able" and seek to prove their competence by "being successful, by outperforming others, or by achieving success with little effort" (Ames \& Archer, 1988). This goal set is encouraged by policies such as class rank which inherently encourage students to compete with each other. In contrast, mastery goal orientation implies that "the process of learning itself is valued, and the attainment of mastery is seen as dependent on effort" (Ames \& Archer, 1988). In short, a student with a performance goal set will be concentrated on proving their ability and outperforming their peers, while a student with a mastery goal set will be primarily focused on learning and retaining the material to advance their general knowledge. Both goal sets are influenced by a variety of factors within the classroom and each results in differing views on academics from the students' point of view. In a later study further exploring the implications of each goal set, Ames and Archer suggest that mastery goal orientation is connected to a "wide range of motivation-related variables that are conducive to positive achievement activity and that are necessary mediators of self-regulated learning" (1992). These findings give insight into the social perspective of students and the classroom environment, with mastery goals having been identified to be more beneficial to the long-term retention of information and understanding of classroom materials.

Another factor possibly contributing to student class choices is how class rank is calculated, which differs between schools because no coherent ranking method has been established nationally. The method by which GPA is computed also determines how the valedictorian is chosen, which could further influence students at the top of the class to enroll in as many high-level courses as possible. The more prevalent ranking procedures include categorizing partially or fully weighted GPA, unweighted GPA, or not supplying a rank at all. In a study conducted by David M. Lang, Assistant Professor in the Department of Economics at California State University, it was suggested that each of these methods are faulty in some way. Unweighted GPA is defined as "equating every grade of " $\mathrm{A}$ " on a student's transcript with 4 grade points, a "B" with 3 points, a "C" with 2 points, and a "D" with 1 point" (Lang, 2007). In short, this system involves no extra points being awarded according to course rigor. In the case study it was found that $12.6 \%$ of the sampled public school districts determined GPAs without weights (Lang 2007). Although this method promotes enrollment in nonacademic and elective courses, it discourages students from taking more challenging classes because they could consequently harm their GPA; specifically, this system rewards students for taking easy classes and therefore achieving better grades, rather than choosing more rigorous courses and having to work harder to maintain an " $A$ ". Lang indicates that students tend to "maximize their benefits at a minimum cost," and will therefore not take harder classes when there is no incentive to do so (2007). Most common is the weighted GPA method, which 71.7\% of the public school districts in Lang's study reported using for their rank calculations; this approach is defined as "augmenting the grade points received for an "A," "B," and so on, in specific courses prior to summing the grade points" (Lang, 2007). Using this system involves adding points to student GPAs to account for the difficulty of higherlevel courses. The major drawback of this calculation method, as Lang points out, is that it can possibly reward 
students for doing less work; if a student takes additional classes, unless they are AP or Honors courses, they will actually harm the student's GPA (2007). A separate study found that this concern with students choosing a "maximum number of courses with higher weights" is a primary reason why many schools seek out alternative ranking methods (Siegel \& Anderson, 1991). This furthers the question of the extent to which students strategically pick courses to boost their GPA, and how GPA calculation influences these decisions.

Due to the differences in student behavior which can result from various rank calculation practices, it is important to outline the specific system used at the school examined in this research study. Student grades are examined with a weighted system, which is as follows: according to the school district's 2019-2020 grading policy, courses are classified as Tier 1, Tier 2, Tier 3, and Tier 4. Tier 1 includes AP and Dual Credit courses which are increased by eighteen points per full semester completed. Tier 2 includes Pre-Advanced Placement and capstone CTE courses which are increased by ten points per semester, and Tier 3 classes, full-year on-level core, elective, and CTE courses, are increased by two points. Tier 4 encompasses the remaining courses in which no points are added to the cumulative grade. This is important to note because it is hypothesized that the extra points granted to higher-level classes motivates students to select those courses in order to positively impact their class rank. It is also worth emphasizing that the school studied is part of the state's admission program, so students in the top $10 \%$ of their class, or top $6 \%$ for more selective schools, are qualified to be automatically admitted into state-funded universities. This may cause increased competition around those areas of the ranking list rather than just at the top of the class. Because the public high school that these subjects attend employs a weighted GPA calculation method, the results of this study cannot be generalized across schools with different rank policies. A cumulation of this information, the evaluation of past research, and the need to address a specific gap, specifically the emphasis on course selection and a narrowed subject pool, led to the formation of the topic of inquiry for this study: "To what extent does class rank competition influence individual class selection by juniors at a high school in the Texas Hill Country?"

\section{Research Methods}

This study explores student perceptions of class rank and the extent to which students choose specific classes in order to maintain or improve their rank. The goal is to understand how students of different academic proficiencies (for example, a student in the top $2 \%$ of the class versus a student in the top 35\%) perceive competition, as well as if they view its possible influence on their class selection to be positive or negative. With the establishment of the performance goal set, it was hypothesized that students with higher ranks would be inclined to take more classes for the sake of their standing and see the system in a more positive light than students of lower rankings.

In order to explore these variables, a two-part mixed-method study was conducted -- this included qualitative interviews and a data analysis of student responses. The research design was inspired by the study conducted by David Bergen \& Helen Cooks; in that study, the researchers used qualitative interviews to examine academic competition among high achieving students of color. Bergen \& Cooks describe the use of interviews which "allow respondents to elaborate, expand, leap into tangents, and reveal more than the interviewer might have requested" (2000). Although more subjects could have been included in this research if a survey was conducted, interviews allowed for students to give thoughtful, detailed answers which contributed more to the understanding of their opinions on class rank. Some interview questions used in this research were modeled after the Bergin \& Cooks study, however a majority were of original design and applied specifically to students of the same grade level and did not account for variables caused by cultural differences. The second part of the research design included an analysis of student responses to identify specific themes with regards to students' opinions on how class rank affects their behavior.

\section{Participants}


Previous research in the field focused on students with successful academic records, either from different schools or in different grades. This study addresses a gap in that it was narrowed to the junior class of one public high school in the Texas Hill Country and included students of various rankings. Juniors were chosen to participate in this study because, at the school studied, it tends to be the year in which students take the highest number of AP classes and heavily seek to improve their rank. Including participants from the same grade level also reinforced the idea that they would have similar experiences of academic competition. This study was also unique because only one school was studied to account for the specific GPA calculation policy used, so all participants would have similar incentive to enroll in higher-level courses. The research was open to any junior willing to participate, as it was necessary to gather students of varying class ranks to draw comparisons between their responses.

Participants for this research were found through word of mouth as well as through Instagram posts describing the nature of the study. Participants were asked to provide their last known class rank, or a range that was within ten spots of their actual rank. Responses were anonymous and student rankings were needed for the quantitative aspect of the research design, so the range option was included in case students were uncomfortable revealing their exact ranking (despite this accommodation, all participants chose to give their exact ranking).

In total, 20 participants were interviewed with class rankings ranging from 1-253, out of a total of 469 students in the junior class (two participants are tied for rank 11). The classification of participants by rank and gender can be seen in Table 1.

Table 1. Classification of participants by rank and gender.

\begin{tabular}{|l|l|l|l|l|l|l|l|l|l|l|l|l|l|l|l|l|l|l|l|l|}
\hline Gender & girl & girl & boy & girl & girl & girl & girl & boy & girl & girl & girl & boy & boy & girl & girl & boy & girl & girl & girl & girl \\
\hline Rank & 1 & 2 & 3 & 9 & 11 & 11 & 12 & 16 & 17 & 19 & 22 & 27 & 34 & 42 & 45 & 56 & 60 & 62 & 146 & 253 \\
\hline
\end{tabular}

Most interviews took place on campus before and after school, however four were conducted over Zoom due to inclement weather conditions and to account for online learners (students at the studied high school had the opportunity to choose in-person or online learning due to COVID restrictions). Students were asked a series of 10 questions and additional probes if their answers required further clarification. Interview questions considered ideas of competition and class selection, including, "What is your number one consideration when choosing your classes for the school year?", and "Do you feel that competition has detracted from your learning or has it enhanced it?". Some questions were written to gather quantitative data to directly answer the research question, while others covered broader topics to introduce more discussion on academic competition and the effects of class rank. The full list of questions used in the interviews can be found in Appendix 1. Each interview lasted from five to fifteen minutes and was recorded to be examined and transcribed on a later date.

Once all participants had been interviewed, their responses were entered into a table in which each student was represented according to their self-reported rank. To address the quantitative aspect of the method, student responses were analyzed to find the percentage of students which responded "Yes" or "No" to each question, and to test the hypothesis that students of higher ranks were more likely to be influenced by their ranking in choosing their courses. For the qualitative element of the method, for each interview question, students were grouped according to similar feedback or common themes throughout their responses; this would provide an understanding of other factors that commonly play into student behavior. The results defined "higher" ranking students as falling within the top $10 \%$ of the class, and "lower" ranking students as anyone below that margin.

\section{Results}

\section{Quantitative Results}


After an initial analysis of student's responses, it was evident that class rank and GPA did have a significant impact on course decisions. Figure 1 illustrates the distribution of responses to question 6, which asked, "Did you take any classes this year specifically to improve or maintain your GPA?". Out of the 20 participants, 17 of the students (85\%) replied "Yes," while only 3 students $(15 \%)$ replied "No." Similarly, when the students were asked, "Are there any classes that you wanted to take but couldn't because they would negatively impact your rank?", 16 of the students (80\%) replied "Yes," while 4 students (20\%) replied "No." (Figure 2). Question 4, which is modeled in Figures 4 and 5 , asked respondents, "Did you take any classes this year because you were interested in them and wanted to learn the material?", to which 16 of the students $(80 \%)$ replied "Yes," while 4 students $(20 \%)$ replied "No." However, out of the students who responded "Yes," 8 students $(50 \%)$ could only name one class that they took because they were genuinely interested in it, 6 students (37.5\%) could name two classes, and 2 students (12.5\%) said they chose most of their classes out of interest.

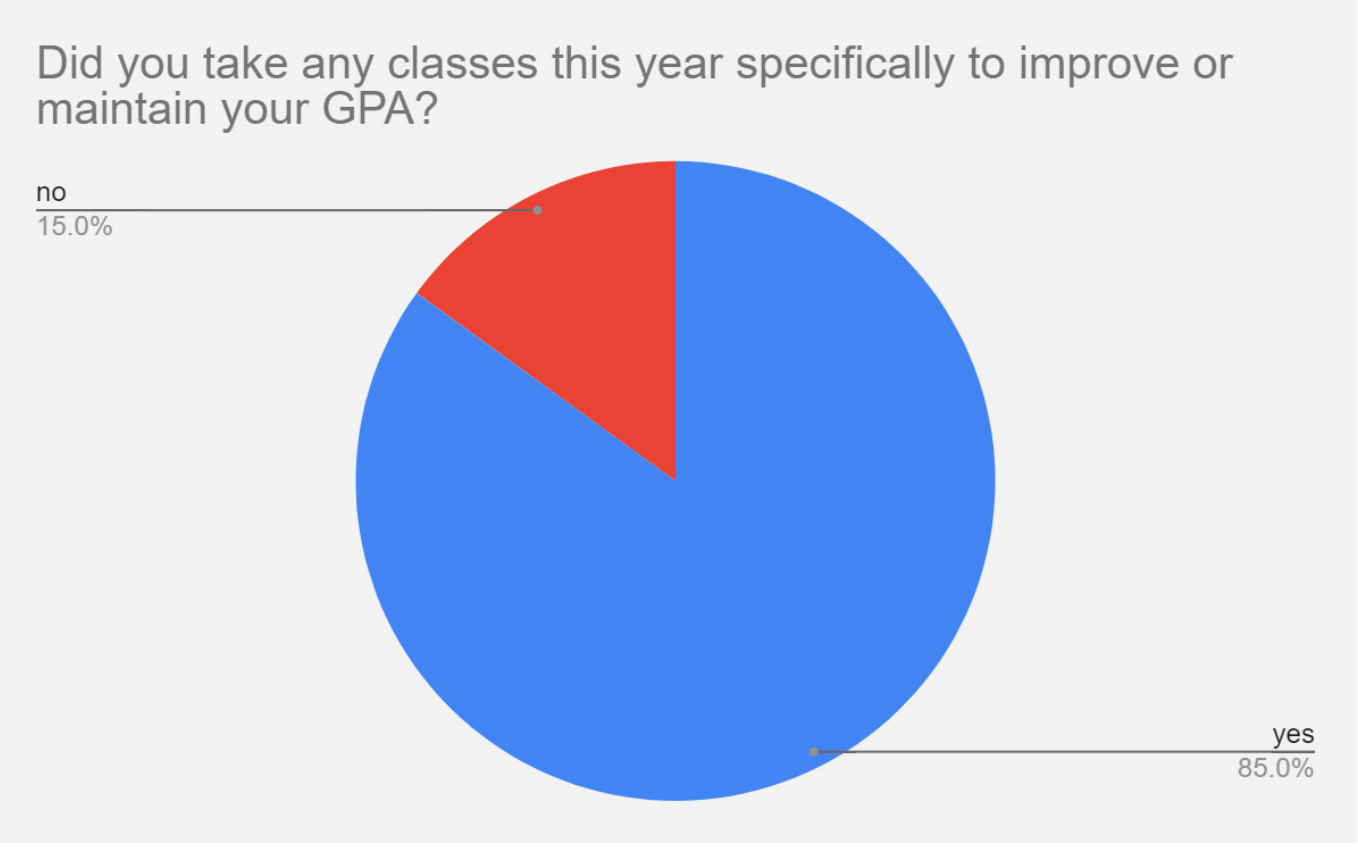

Figure 1. Did you take any classes this year specifically to improve or maintain your GPA? 


\section{Are there any classes that you wanted to take but couldn't} because they would negatively impact your rank?

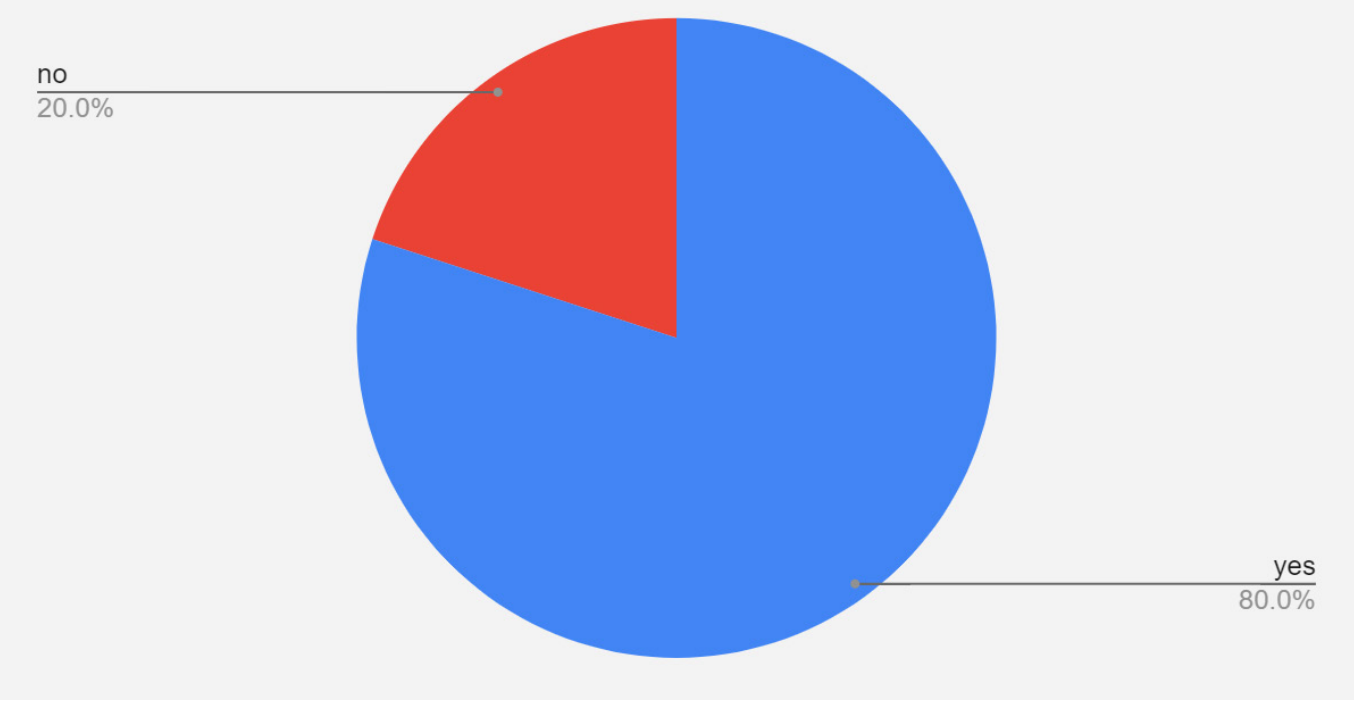

Figure 2. Are there any classes that you wanted to take but couldn't because they would negatively impact your rank?

Did you take any classes this year because you were interested in them and wanted to learn the material?

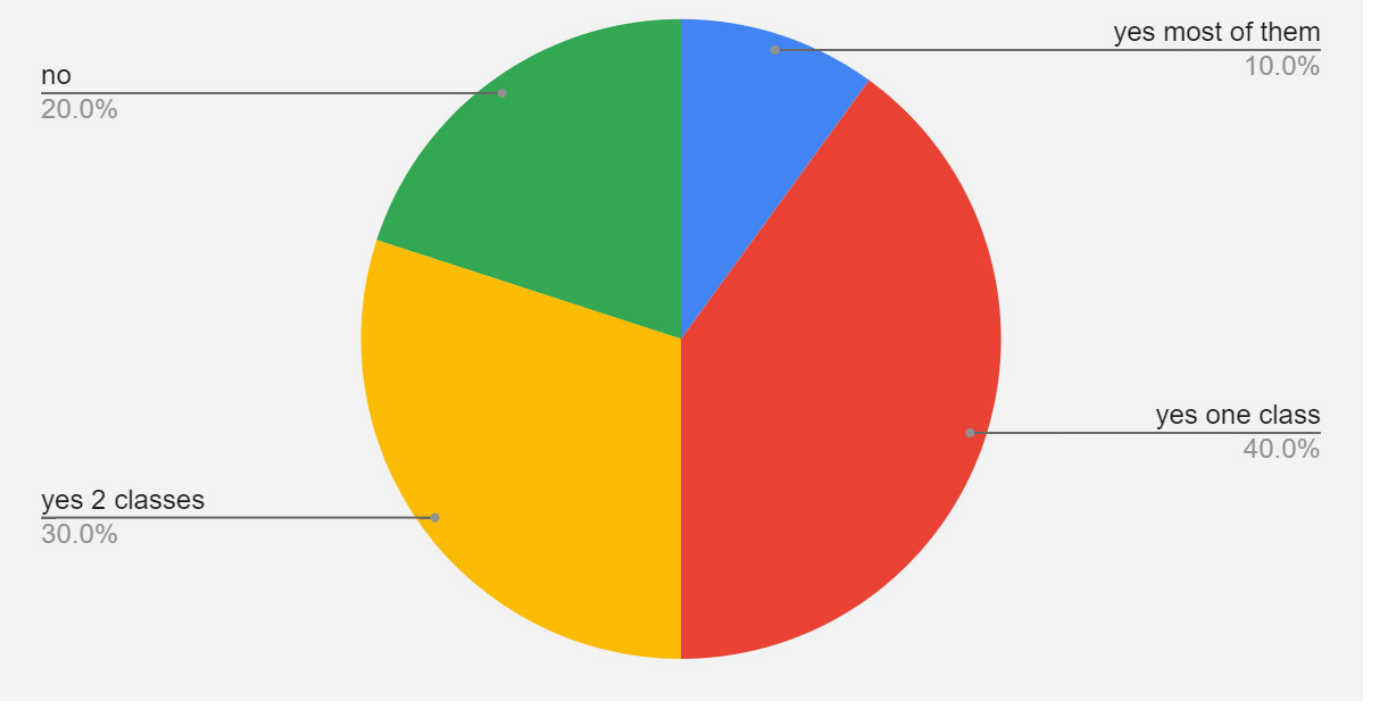


Did you take any classes this year because you were interested in them and wanted to learn the material?

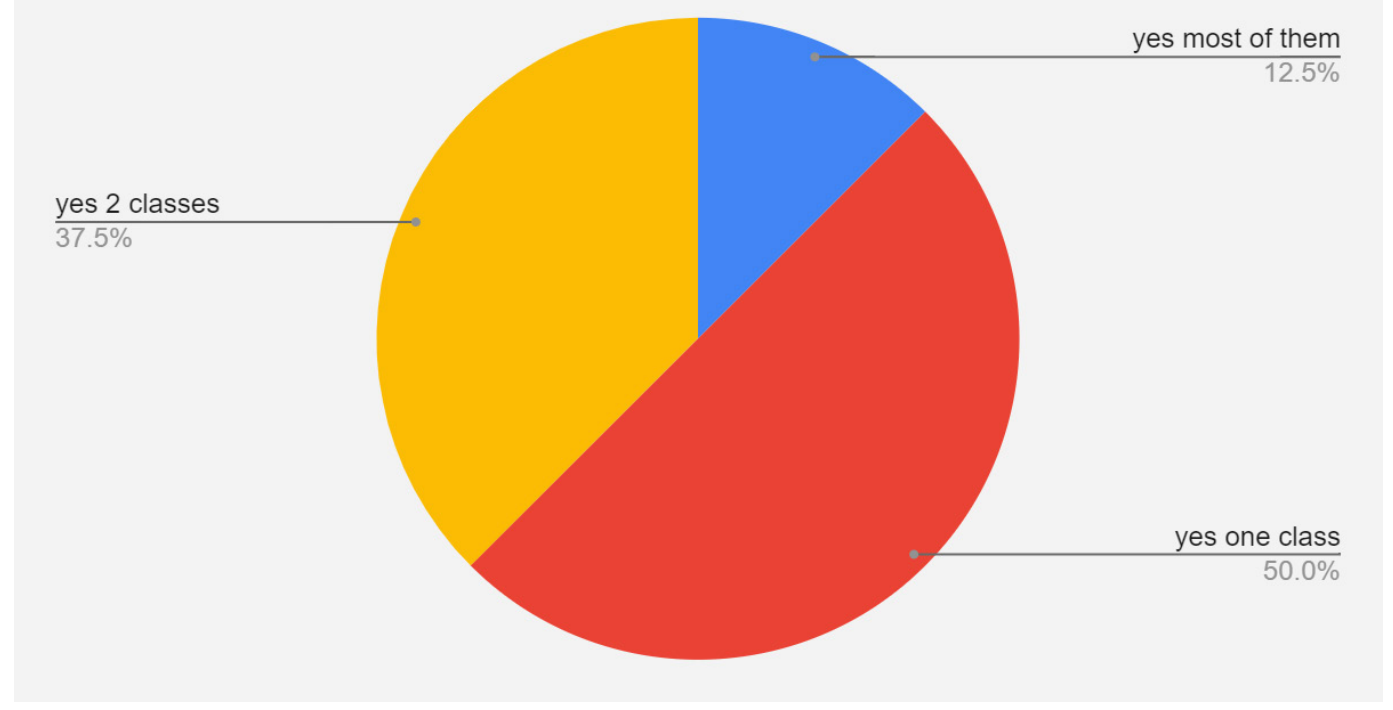

Shown in Figure 5, responses to questions 4-6 were converted to a numerical scale to determine if there was a correlation between student behavior and their class rankings. "Yes" responses were represented with the number 1 , while "No" responses were shown as a zero. 


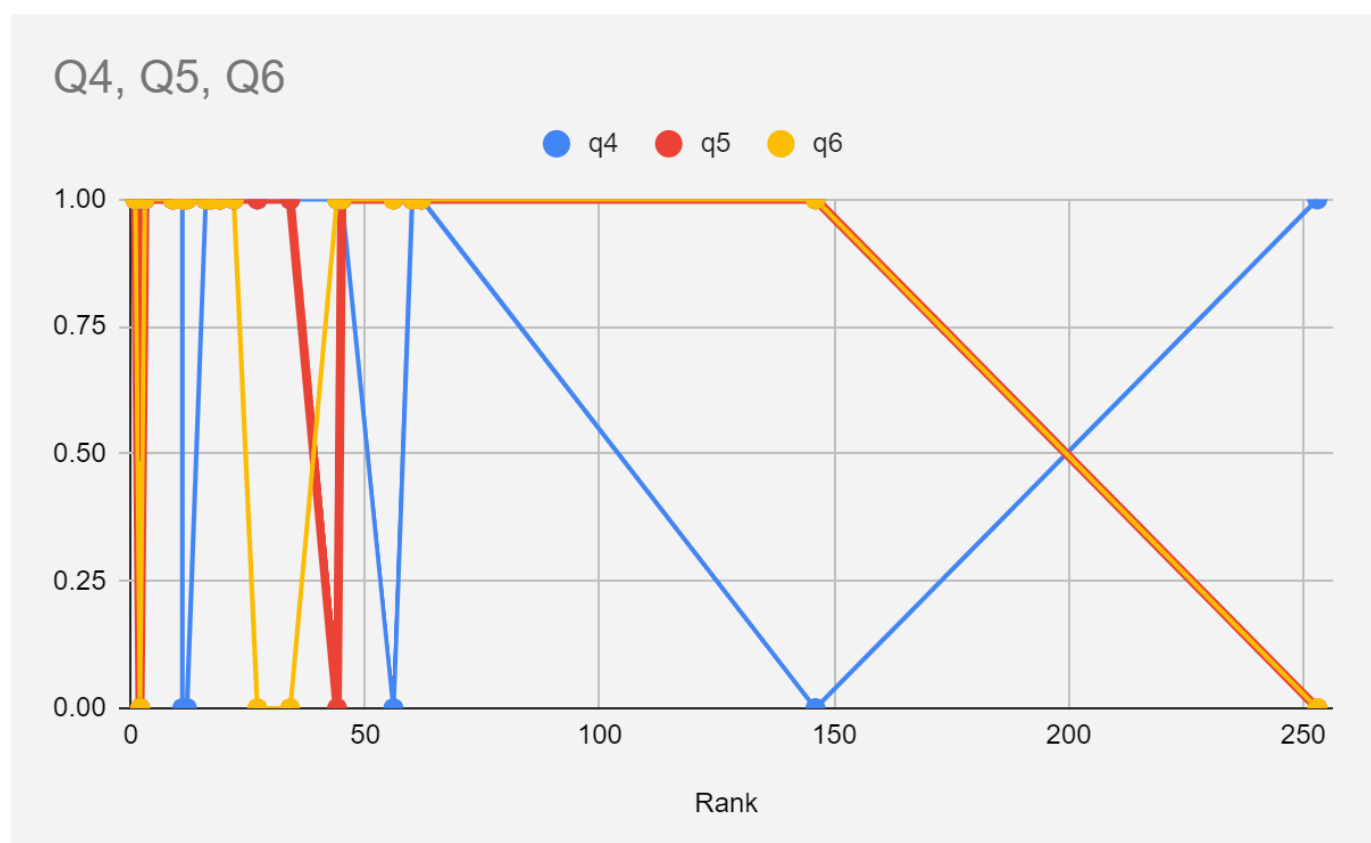

Figure 5 shows no apparent correlation between the participants' positions in the class and their decisions regarding their course choices. "Yes" and "No" responses were relatively scattered throughout the data set, regardless of the students' rankings.

\section{Qualitative Results}

Interviews were transcribed and coded using Braun and Clarke's (2006) reflexive thematic analysis approach. Three themes emerged as most prevalent within student responses: class rank as an academic motivator, effects of rank on mental health, and student suggested improvements to the ranking system. Participants are represented in the transcripts according to their rank (ex. a student ranked third will be represented as 3). Two participants were tied for rank number 11 , so they are represented in the findings as $11 \mathrm{~A}$ and $11 \mathrm{~B}$.

\section{Class Rank as an Academic Motivator}

All 20 students signified rank as a factor to push them to achieve better grades, although opinions on whether it occurred under positive or negative circumstances varied. When participants were asked if they felt their grades would be better or worse if their school didn't release class rank, 14 students responded that their grades would be worse. Many attributed this to the idea that because their rank is an indicator of where they stand in comparison to their peers, not knowing it would take away their drive to succeed academically.

Interviewer (Int): Do you feel like your grades would be better or worse if your school didn't release class rank?

(Student) 9: I think the motivation of seeing my class rank, and then being able to work on it, know how I can improve, or just saying, I like where I'm at, actually helps me, and so I think it might be worse if I didn't know. 
11A: Honestly probably worse, because when they release it, it makes me aware of the fact that there is competition and the fact that my grades are somewhat important, so I'm glad that they release it.

Other participants acknowledged that their rank did influence their grades, however their experiences reflected more negatively.

11B: To be honest they might actually be worse because I wouldn't be aware of what other people were making so there wouldn't be a standard to hold myself to. Because right now I get the impression of, if I have a class that's below a 95, well then that's horrible because everyone else in that class has above a 95...So if we didn't have class rank then I actually think that they might be a little bit worse because there wasn't that competitive aspect.

9: I think that because I'm so competitive it's definitely driven me to work harder and get better grades but, although it's helped my grades I think it's had negative impacts elsewhere in my life. Like mental health wise, if I didn't care so much about my class rank I might take some easier classes... and, I mean in turn it honestly might end up hurting my grades.

Accounts of negative experiences or feelings of little motivation tended to increase with students who were lower in the class:

42: It could go either way. Because I feel like rank, for some people, obviously if you're number one you're like freaking out right, because you don't want to lose your spot, but then if you're 199, you're probably like ok well... I'm not gonna get there anyways.

Int: If you could make the ranking system at your school, what would you change?

62: I just feel like it's very degrading especially if you're on the lower half of it, I just think that's really discouraging, and it kind of makes it seem like if you're already low, then there's no point in working my way up, versus if you're up you have this motivation to work your way up, but I just think motivation should come from within the individual not just because of a number.

Int: So you feel like it's motivating for people higher up but degrading for people lower down?

62: 100 percent. Because if you're already at the top, you'll work harder to stay at that top or, you know, push past it. But if you're already at the bottom it's kind of like, I'm stuck here, so there's no really point in moving forward.

Interview excerpts clearly displayed significant discrepancies between high and low ranking students regarding academic motivation, some seeing it as inspiring while others view it as demoralizing.

Influence of Class Rank on Mental Health

Perceptions of stress and anxiety caused by class rank varied among the participants. Some students acknowledged that it caused pressure to a minimal extent but was manageable, while others appeared to be either affected significantly mentally or not affected at all.

Int: Do you feel a pressure to keep up with AP classes?

1: It depends...Sometimes I do, and sometimes it's kind of more- I think I used to, and I think this year, as it's gone on and as it's been stressful, I have kind of relaxed and I've been like, it's not important to have that much anxiety about that.

When asked about ranking competition's effects on their learning, student 3 stated, 
3: Ok, first of all I'd say the competition's not, with people, I don't compete with actual people, I really don't care. I'd say the competition is more just trying to be number one for school, so I don't think it's overly pressuring, and it definitely doesn't have an effect, for me at least.

Int: Does the competition weigh on you or does it not really affect you?

27: I mean it affects me a little bit, you know of course I have self-doubts about if I'm smart enough or not but, I don't have mental health issues because of my grades or anything like that.

Other participants reported the academic competition as having a more substantial impact on their mental well-being.

Int: Do you have a high or low breaking point with regards to stress?

9: I'd like to think I'm resilient but, I honestly don't think I am. Or maybe I'm just under so much pressure that I'm already at that edge, but the pressure from school definitely gets to me, all the time...I have unrealistic stress for things like tests and quizzes and I am always thinking about how one grade can affect my entire GPA, like if I bomb a test, that's gonna lower my grade in the class, and a lower grade in the class is gonna lower my GPA, and the lower GPA is going to lower my rank, it's like a snowball effect that's constantly in the back of my mind.

Int: Does class rank put a significant pressure on you?

62: Definitely, but I think it's within the students and it's pretty self-induced. I don't think the teachers are necessarily putting the pressure on us in terms of rank, but I think that the students bring it upon themselves to be very overwhelmed with rank and the students cause a frenzy over it and over what your position is, and that's like a direct correlation to your intelligence, which I just don't think is fair.

Int: Overall do you see rank positively or negatively?

12: Negatively definitely because the amount of time I spend thinking about rank... or whenever our ranks get released every semester, that's all I think about until I get it, and then when I get it sometimes I'm disappointed, sometimes I'm happy, it's scary how much it impacts my mood for the day, and it just causes so much unnecessary stress.

Int: Has competition positively affected your grades or has it had more debilitating impacts?

253: I think it's had more debilitating impacts. I think it's just because, always being stressed out about where, if I'm not doing well, my rank's gonna drop and my GPA is gonna drop, and just being in such a competitive area, it's always stressful, keeping a good grade.

\section{Student Suggested Improvements}

Each participant was asked what they would change about their school's ranking system if they had the opportunity. 7 out of the 20 participants mentioned decreasing the weight of 18 extra points on AP and Dual Credit classes, and 4 students suggested releasing rankings to only the top $10 \%$ of the class. 4 students expressed that they wanted to participate in more sports and electives without harming their rank, and 2 others said they wished the atmosphere was less competitive. 4 participants said they would make no change to the system, while 3 others said they would get rid of it entirely.

3: I would drop the number of electives that factor into it. I'd keep the 18 points and everything, but that way, you can still take double blocked footballs, or orchestra or whatever you want to take, and not worry about it.

9: I'd say as much as I like the 18 extra points system, and the extra points for honors classes that, if I could change something I would put less weight on those AP classes. I think it is fair to give them the extra points because AP kids do work really hard in those classes, but 18 extra points is an insane amount...and there are incredible classes here 
that are on level classes that you don't get extra points for, and so if we weighted those little bit differently to put less emphasis on kids taking those classes for the extra points, I think it would definitely help. The other thing is providing class rank, I think that...if we didn't tell kids their class rank until their junior year...that it would definitely help kids a lot and again deemphasize taking those hard classes just for the points.

45: I would probably do only top 10 or $15 \%$... I definitely like knowing that I could probably get into college today, but I know a lot of kids feel stressed about it.

2: I like the ranking system for our grade specifically. I know that they have a different ranking system for grades below us, but from what I've learned about the younger grade's ranking system, it's difficult for them to, since they don't get their ranks, know what's going on, and so I don't think I would change our ranking system.

253: I think I would just get rid of it.

Interview transcripts revealed differences in student opinions that the quantitative data was unable to provide. Although high and low ranking students behave similarly for the sake of their GPA, their overall opinions about class rank varied greatly.

\section{Discussion}

\section{Findings}

The goal of the study was to examine the extent to which class rank competition influences student class selection, and to determine if its effect varies among students of different rankings. After analyzing participant responses, it was found that ranking and GPA played a significant role in many student's decisions regarding their courses, specifically in encouraging them to take AP, Dual Credit, and Honors classes. This is confirmed by over $80 \%$ of the participants affirming that their rank is a contributing factor in their course selections (Figures $1 \& 2$ ). Additionally, 11 out of the 20 students cited their rank and GPA as one of their number one considerations when choosing their classes for the school year. These findings support assertions in previous research that class rank promotes performance goal structures and consequently increases competition among students (Ames \& Archer, 1988, Bergin, 1995). Although class rank was indicated as an influential factor in course selections, there was no apparent correlation of a higher tendency to choose classes for rank purposes among higher ranked students, disproving the hypothesis (Figure 4). In short, the study reached a new conclusion that a majority of the students consider their rank when choosing their courses, regardless of whether they are high or low ranking.

The qualitative results provided a detailed insight into the personal feelings of the participants regarding the ranking system. Many students referred to their rank as a means to propel academic success and keep themselves accountable for their grades. However, lower ranking students perceived it as having quite the opposite effect; providing that the comparison was somewhat belittling, participants felt that if they were already low ranking, there would be no purpose in attempting to improve. This finding asserts that class rank is constructive to a definitive group of people, but may inhibit work ethic for others. The conclusion is cohesive with the pre-existing research, which found that when competition was stressed, many students quit if they were not winning (Bergin \& Cooks, 2000). The same conclusion was also drawn by Monica Kowalski and Andrea Christensen of The University of Notre Dame, who determined that student engagement in competition relied on their perceived level of competence, and competitive environments proved to be detrimental for students with low perceptions of ability (2019). In regards to mental health, the burden of class rank appeared to depend more on the nature of the student's personality rather than their academic status: students who prioritized their grades were more prone mental health issues due to their rank than those who 
were less concerned with their standing, and there was no correlation found between students of higher or lower rankings being more prone to issues with mental health. Opinions about an ideal ranking system varied greatly, but a majority of the students expressed a desire to be able to take more sports and elective courses without undermining their rank, but still have some weight added to higher level courses to keep them incentivized.

\section{Limitations}

Because of the decision to conduct qualitative interviews, the sample size was limited, and the findings of this research would have greater statistical significance if more of the junior population were able to be interviewed. Although this is a significant limitation, it was also understood that detailed student explanations would be more valuable to understanding student perceptions and meeting the goal of the research. Other limitations included the use of selfreported class rankings, as the validity of these values lies entirely in the honesty of the participants, and the tendency for students to not want to reveal their ranking at all, as it is a sensitive topic for many students who fear judgment according to their academic status. A list of updated rankings of junior students was not available, so the use of their personally reported ranking was necessary in order to quantify the results of the interviews. Students who agreed to participate in the research also tended to be higher up in the class, with 16 out of 20 subjects being above rank 60 . There was also a disproportionate number of male versus female participants ( 5 male, 15 female). If the subject pool contained more variety either through rankings or gender, more comparisons could be drawn between their responses.

\section{Implications}

The significance of these findings may be influential in prompting schools to rethink the nature of their class ranking systems and GPA calculation methods. Understanding the effect rank has on student behavior provides the mechanisms needed to adjust weights of various classes to best fit student needs. Class rank continues to serve as a primary predictor of college success, and will likely have a greater influence on college admissions with many universities becoming test optional (Niu \& Tienda, 2011). The findings of this research can aid in determining ranking systems that are both accurate representations of ability as well as provide equal benefit to students. Additionally, teachers can emphasize or deemphasize academic competition in order to increase motivation. Knowing that higher performing students are typically going to benefit from academic competition, teachers in higher level AP courses can encourage competition among their students to garner more motivation in their learning. Contrastingly, a teacher in a lower-level course may emphasize the mastery goal set over competition in order to motivate their students to want to learn.

\section{Future Studies}

Specificities of this study could be expanded into future research to address a different pool of subjects. A high school with an unweighted ranking system or no ranking system at all could be examined to determine student behavior based on a different set of incentives. Students of different grade levels or from different schools could also be studied to draw comparisons among more variables. Researchers could also go into depth about the different behaviors of males versus females due to academic competition to identify if there is a correlation of responses based on gender. Addressing larger populations of high schoolers will allow for a greater understanding of the influence of class rank and enable educators to implement systems that benefit all student populations. 


\section{Acknowledgments}

The author would like to thank the faculty, staff, and students who contributed to and participated in this study. Additional gratitude is extended to the faculty advisor on this project, Ms. Kimberly Grosenbacher.

\section{References}

Ames, C. (1992). Classrooms: Goals, structures, and student motivation. Journal of Educational Psychology, 84(3), 261-271. Retrieved October 4, 2020 from https://doi.org/10.1037/0022-0663.84.3.261

Ames, C., \& Archer, J. (1988). Achievement goals in the classroom: Students' learning strategies and motivation processes. Journal of Educational Psychology, 80, 260-267.

Bergin, D. A., \& Cooks, H. C. (2000). Academic Competition among Students of Color: An Interview Study. Urban Education, 35(4), 442-472. https://doi.org/10.1177/0042085900354004

Bergin, D. (1995). Effects of a Mastery versus Competitive Motivation Situation on Learning. The Journal of Experimental Education, 63(4), 303-314. Retrieved October 4, 2020, from http://www.jstor.org/stable/20152461

Braun, V., \& Clarke, V. (2006). Using thematic analysis in psychology. Qualitative Research in Psychology, 3(2), 77-101. https://doi.org/10.1191/1478088706qp063oa

Class rank \& college admission. (2020, October 26). Retrieved April 06, 2021, from https://professionals.collegeboard.org/guidance/applications/rank

Gilman, D. A., \& Swan, E. (1989). Solving G.P.A. and Class Rank Problems. NASSP Bulletin, 73(515), 91-97. https://doi.org/10.1177/019263658907351515

Judith Siegel, C. (1991). Considerations in Calculating High School GPA and Rank-in-Class - Judith Siegel, Carolyn S. Anderson, 1991. Retrieved September 20, 2020, from https://journals.sagepub.com/doi/pdf/10.1177/019263659107553716

Kowalski, Monica; Christensen, Andrea L. (2019). "No One Wants to be a Loser:" High School Students' Perceptions of Academic Competition. Mid-Western Educational Researcher, Vol. 31 Issue 4, p389-406. 18p. Retrieved October 4, 2020, from https://www.mwera.org/MWER/volumes/v31/issue4/V31n4-KowalskiFEATURE-ARTICLE.pdf

Lang, D. (2007). Class Rank, GPA, and Valedictorians: How High Schools Rank Students. American Secondary Education, 35(2), 36-48. Retrieved September 16, 2020, from http://www.jstor.org/stable/41406287

Niu, S. X., \&amp; Tienda, M. (2011, August 2). Test Scores, Class Rank and College Performance: Lessons for Broadening Access and Promoting Success. Retrieved September 20, 2020, from https://www.researchgate.net/profile/Sunny Niu2/publication/240310148 Test Scores Class Rank and College P erformance Lessons for Broadening Access and Promoting Success/links/56ab48ca08ae8f386568cabf.pdf 